VORTRÄGE

AUS DEM WARBURG-HAUS

BAND 6 


\author{
VORTRÄGE \\ AUS DEM WARBURG-HAUS \\ BAND 6 \\ HERAUSGEGEBEN VON \\ WOLFGANG KEMP \\ GERT MATTENKLOTT \\ MONIKA WAGNER \\ MARTIN WARNKE
}




\title{
SIMONE MICHEL
}

Der Pantheos auf Magischen Gemmen

$$
\text { STEPHEN BANN }
$$

Der Reproduktionsstich als Übersetzung

\author{
URSULA HARTER \\ Le Paradis artificiel \\ Aquarien, Leuchtkästen und andere Welten \\ hinter Glas

\section{ULRICH RAULFF} \\ „Idea vincit“: Warburg, Stresemann \\ und die Briefmarke \\ SILVIA EIBLMAYR \\ Hysterie, Körper und Technik in der Kunst \\ des 20. Jahrhunderts
}

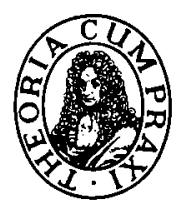

Akademie Verlag 
Redaktion: Catharina Berents

ISBN 3-05-003768-7

(C) Akademie Verlag GmbH, Berlin 2002

Das eingesetzte Papier ist alterungsbeständig nach DIN/ISO 9706.

Alle Rechte, insbesondere die der Übersetzung in andere Sprachen, vorbehalten. Kein Teil dieses Buches darf ohne schriftliche Genehmigung des Verlages in irgendeiner Form - durch Photokopie, Mikroverfilmung oder irgendein anderes Verfahren - reproduziert oder in eine von Maschinen, insbesondere von Datenverarbeitungsmaschinen, verwendbare Sprache übertragen oder übersetzt werden.

Satz: Werksatz Schmidt \& Schulz, Gräfenhainichen Druck: Primus Solvero, Berlin

Bindung: Druckhaus „Thomas Müntzer“, Bad Langensalza

Printed in the Federal Republic of Germany 